\title{
La circunstancia, una oportunidad para educar
}

\author{
Carlos Alberto Hernández García* / carlos_alberti@hotmail.com
}

Yo soy yo y mis circunstancias.

José Ortega y Gasset

La anterior es una frase muy conocida que aparece en el primer libro de Ortega y Gasset, Meditaciones del Quijote, y creo que resultaría muy importante si los maestros la tuviésemos en cuenta al momento de ocuparnos de la educación del niño. Cada persona es un ser totalmente diferente de los demás y tiene sus cualidades y defectos, físicos o morales, muchos de ellos innatos; además a cada quién le corresponde hacer frente a sus circunstancias sociales particulares, y todo esto implica, fuera de aceptación por parte del sujeto, tolerancia por parte de aquellos con quienes convive. La tendencia general se dirige hacia la envida por la suerte ajena, pero lo lógico sería idealizar la realidad; tenemos mucho que aprender de nuestras circunstancias, no las despreciemos.
Seguramente cada uno de nosotros puede dar testimonio de muchas personas conocidas que han logrado superar sus defectos, muchas veces físicos, y sus circunstancias, Ilegando a sobresalir dentro de la sociedad. Sin duda, estas personas no son las que han perdido su tiempo envidiando la suerte ajena o aceptando simplemente su defecto, conformándose con sus limitaciones y esperando compasión.

La circunstancia que nos acompaña en cada momento debe servirnos para crecer, para abrirnos camino, para superarnos, avanzar y servir mejor a los demás, pero sobre todo para aumentar nuestro propio conocimiento. Todos los verbos que acabo de emplear implican acciones de superación que deben ser conocidas muy bien por el maestro, particularmente el de primaria, y muy especialmente el maestro de español. A ellos me dirijo en especial, ya que en sus manos descansa una herramienta útil para hacer pensar: la redacción.
Los niños deben crecer sin complejos, y para esto deben ser conscientes de su realidad; esa realidad que desde el momento en que son capaces de redactar, deben aprender a compartir con sus compañeros mediante ensayos y escritos que, poco a poco, se verán enriquecidos con descubrimientos que normalmente deben resultar de una dedicación especial en el pensar y el escribir sobre aquello que toca lo más profundo de su ser. Sin embargo, debo aclarar que cuando me refiero a la escritura no la encasillo necesariamente en su ejercicio manual, pues el computador ha hecho que escribir sea un placer que afortunadamente nuestros jóvenes dominan ya desde niños.

Al escribir normalmente nos exponemos a la crítica, por lo que debemos llegar a descubrir su valor, saber aceptarla y aprender a realizarla en forma constructiva. No olvidemos que, como se anuncia en Mateo 12: 34, "de la abundancia del corazón habla la

\footnotetext{
*Licenciado en Matemática y Física de la Universidad de Antioquia; antiguo Profesor de la Normal Superior La Hacienda, actualmente pensionado.
} 
lengua". Al educador le corresponde crear un clima de tolerancia en el aula que permita a cada uno de sus educandos manifestarse sin temor, tal como es. La burla entre compañeros debe desaparecer, pues mientras más natural sea el ambiente, mejor será la acción educadora; el puritanismo y el autoritarismo son elementos que terminan atrofiando la personalidad del niño.

Personalmente nunca me entusiasmó escribir durante mis años de escuela, si lo hacía era únicamente por cumplir, sólo hasta ya muy tarde fue que la escritura tomó su lugar, el día en que un amigo me sugirió que enviara un escrito que le había mostrado a "Lectores escriben" de El Heraldo de Barranquilla1. He continuado haciéndolo hasta el presente y debo confesar que, sin contar con la gran satisfacción que me ha representado, ha contribuido a aumentar mis conocimientos y, lo más importante, a mantener mi pensamiento vivo. Que sea esta la oportunidad para agradecer al periódico El Heraldo por haberme soportado y, muchas veces, orientado, aunque en forma indirecta.

\section{Mi circunstancia}

A continuación quiero compartir con el lector especializado, la audiencia general de la revista Nodos y Nudos, es decir, los maestros, los descubrimientos que he logrado a partir de la circunstancia que me ha acompañado durante mis últimos

\footnotetext{
1 El texto puede ser consultado en El Heraldo, "Lectores escriben", 23 de abril de 1990, "La Resurrección del Pitecántropos".
}

años: la sordera. Sin embargo, me atrevo a pensar que este ejercicio puede ser útil no sólo para quienes se dedican a la educación, sino para especialistas en audiología, que seguramente encontrarán provechosa la experiencia directa de uno de sus pacientes y les permitirá aumentar sus conocimientos.

Todo cuanto escribo a continuación es fruto de la investigación que me he impuesto en busca de una explicación para el estado que padezco; es mucho lo que he aprendido, comenzando por entender que mi sordera no corresponde al profundo silencio que padecen quienes sufren de la sordera clásica, sino que se ajusta a una condición peor, pues, aunque escucho un ruido fastidioso, este carece totalmente de significado, ya que no distingo los diferentes sonidos.

Mis averiguaciones me han permitido descubrir que no soy el único que padece esta forma de sordera, y lo raro es que puedo dialogar sin ningún problema con otras personas de mi edad que sufren del mismo mal. Al final he llegado a aceptar el diagnóstico que me diera el médico el día que me hice examinar del oído preocupado por lo que todos decían: que yo estaba sordo. "Usted no es sordo", me dijo el especialista.

En ese momento, al detectar la contradicción, muchas cosas se me ocurrieron: el examen fue mal practicado; los instrumentos no funcionaron adecuadamente; este médico está loco; no me recetan audífonos por evitar un gasto a la EPS. Sin embargo, al final, mi forma de pensar cambió: es posible que existan distintas clases de sordera conocidas, muy bien, por los especialistas; pero entonces haría falta que se dieran a conocer, que se especificaran, ya que mi mal no se puede llamar sordera, y lo más importante, que se indicaran formas de prevenirlas.

Llegué al convencimiento de que muchas veces hay que buscar la causa de las enfermedades en degeneraciones diferentes a las corpóreas. $\mathrm{La}$ causa de mi sordera no radica en el tímpano, he descubierto que la culpa de mi sordera está mi forma de pensar y de actuar. En algún momento me negué a seguir "metido en la onda”. ¡Exactamente así! Sucede que todo va cambiando y en el momento en que las personas se cansan de las innovaciones o se niegan al cambio, naturalmente, tienen que quedar rezagadas. Seguramente el mismo fenómeno tiene que ver con todos los sentidos, pero sin duda el que más se ve afectado por esta situación es el del oído.

Trato de explicar mi pensamiento: las formas de expresarse van cambiando durante la vida de una persona, y esto sin que ella caiga en cuenta. Por moda o por capricho, especialmente de los jóvenes, el lenguaje popular va adoptando nuevos estribillos que las personas, especialmente aquellas que se precian de cierta educación, 
se niegan a aceptar y a emplear, tratando de ignorarlos. También por exigencias de la sociedad, tal vez del estrés que cada día aumenta, se habla más rápido; sería bueno que estudiosos del tema lograran comparar la velocidad del lenguaje manejado por el común de las personas a principios del siglo XX, con la del momento actual.

A lo anterior habría que agregar la influencia de las tecnologías de la comunicación, no es lo mismo haber visto nacer la televisión, que haber nacido viendo la televisión. Existe un abismo entre las personas implicadas en una de estas circunstancias, yo pertenezco al primer grupo, me correspondió aprender a ver la televisión, y la única forma que se me ocurrió, y se me sigue ocurriendo, para verla, es dedicarme por completo a ver televisión, haciendo caso omiso de mi entorno.

Me fastidia sobremanera que me interrumpan mientras veo televisión, y les cuento que por lo general oigo y entiendo muy bien las diferentes presentaciones, a no ser que alguno de quienes nacieron viendo televisión me interrumpa con sus comentarios. Ellos no tienen problema alguno en ver y conversar en voz alta al mismo tiempo; con frecuencia esto me lleva a admirar la capacidad de los jóvenes que me rodean y a considerarlos muy inteligentes, creo también que ellos, al verme en apuros, deben pensar que están frente a un retardado mental; y qué no dirán cuando me ven manejando el teléfono celular, que posiblemente tampoco logro oír por el mismo desinterés que me ha representado esta innovación, pues para mí, implica una dependencia que no soporto.

Definitivamente existe un abismo entre los viejos, que nacimos antes de los medios modernos de comunicación, y los jóvenes. Ellos no tienen ningún problema en conversar mientras ven la televisión o mientras escuchan en la emisora, la "música de negros", como se le llamó en alguna época en el interior del país a la música costeña, la misma que hoy ha llegado a imponerse. A Dios gracias, en algún momento he llegado a aceptar el Rap.

En los jóvenes detecto grandes y envidiables habilidades, pero también, pensando en mi problema de sordera, he encontrado que han desaparecido aquellas personas que gozaban de la misma habilidad que, según aprendimos en la escuela, distinguía a nuestro libertador Simón Bolívar: "Ser capaz de dictar a tres amanuenses a la vez" (Henao y Arrubla, p. 299). Esta frase, que no he olvidado a pesar de los años, se relaciona con el problema que nos atañe; la aprendí de mi maestro cuando cursaba la primaria, por eso pensé que podría encontrarla en la historia patria de Henao y Arrubla, y en efecto, recurriendo al computador, allí la encontré.
Me sorprendió haber caído en cuenta de algo que debí aprender desde que estudié las nociones de Historia de Colombia: el autor de este libro no es uno sólo, como pensaba, sino dos personajes que contribuyeron con su obra a la celebración del Centenario de la Independencia: Jesús María Henao y Gerardo Arrubla. No sería nada raro que más de uno de mis lectores salga en este momento de la misma confusión, sugerida por la existencia de apellidos compuestos, como Ortega y Gasset.

Continuando con mi investigación, pude comprobar que "amanuense" es una palabra muy castiza, tanto, que es admitida por mi computador, pero ya desconocida por muchos de nuestros jóvenes menores de cincuenta años, y posiblemente manejada sólo por abogados. Existe en el diccionario y significa: "Persona que escribe a mano lo que se le dicta". El hecho de que esta palabra suponga escribir a mano, justifica en muchos sentidos su desuso, fácilmente se puede deducir que la causa de su desaparición radica en la puesta en marcha de una de las primeras tecnologías: la máquina de escribir.

Sucede entonces que los jóvenes se adaptan fácilmente a los cambios sugeridos por la moda o por ellos mismos, y lo normal es que las personas de edad se aferren a sus costumbres y se resistan al cambio; de esta resistencia nacen las chocheras, que normalmente nos anuncian que nos acercamos al día final de nuestra vida. Les cuento que como docente que fui, pude escapar de ellas, hasta el día en que me jubilaron. 


\section{Pinterias}

\section{Perdón y cuenta nueva}

Generosamente perdono a todos los que me hablan el hecho de no poderles entender; menos a quienes se dedican a la actuación, porque lo normal sería que antes de ejercer hayan seguido algún curso de vocalización para ser entendidos por todo el auditorio. Por fortuna, a la mayoría de ellos les oigo perfectamente, entiendo sus mensajes y disfruto escuchándolos. A mis amigos y a mis familiares les pido que perfeccionen su discurso cuando me hablen, sé que muchos lo pueden hacer, he detectado su capacidad de adaptación, los he visto hablar rápido o despacio, claro o enredado, de acuerdo al interlocutor.

Yo también fui joven, pero primero niño, y recuerdo la dificultad que tenía para pronunciar bien cuando hablaba con mi padre; más adelante comprendí la razón: me sentía cohibido, tal vez por el respeto que le tenía; con mis compañeros hablaba normalmente y sin problema. La circunstancia de haber optado por la profesión de educador me sirvió definitivamente para aprender a pronunciar claramente las palabras y hacerme entender por todos.

\section{Conclusión}

Con este articulo, fuera de hacer participes a mis lectores de las conclusiones a que he llegado, quisiera dar a entender que cualquier persona, pensando en sus problemas, en forma positiva y escribiendo, puede lograr gran satisfacción personal al hacer descubrimientos que no sólo les serán útiles a ella misma, sino que pueden llegar a constituir datos valiosos para la ciencia.

En efecto, creo en este momento, colaborar con los especialistas en audiología al contarles lo que pienso sobre mi sordera, pero se me ocurre que se hace necesaria una colaboración semejante, de quienes padecen otras de esas enfermedades modernas como el estrés, que podría disminuir en quien lo sufre, por el mero hecho de investigar sobre sus causas, o el Alzhéimer, naturalmente en su etapa inicial, porque cuando ya se haya desarrollado creo imposible que exista un sujeto que pueda seguir mi propuesta.

\section{Referencias}

Henao, J., y Arrubla, G. (1910). Historia de Colombia para la enseñanza secundaria. Bogotá: Imprenta Nacional, 299.

La Biblia. Mateo 12: 34.

Ortega y Gasset, J. (2004). Obras Completas, v. I. Madrid: Taurus, Fundación José Ortega y Gasset, 757. 


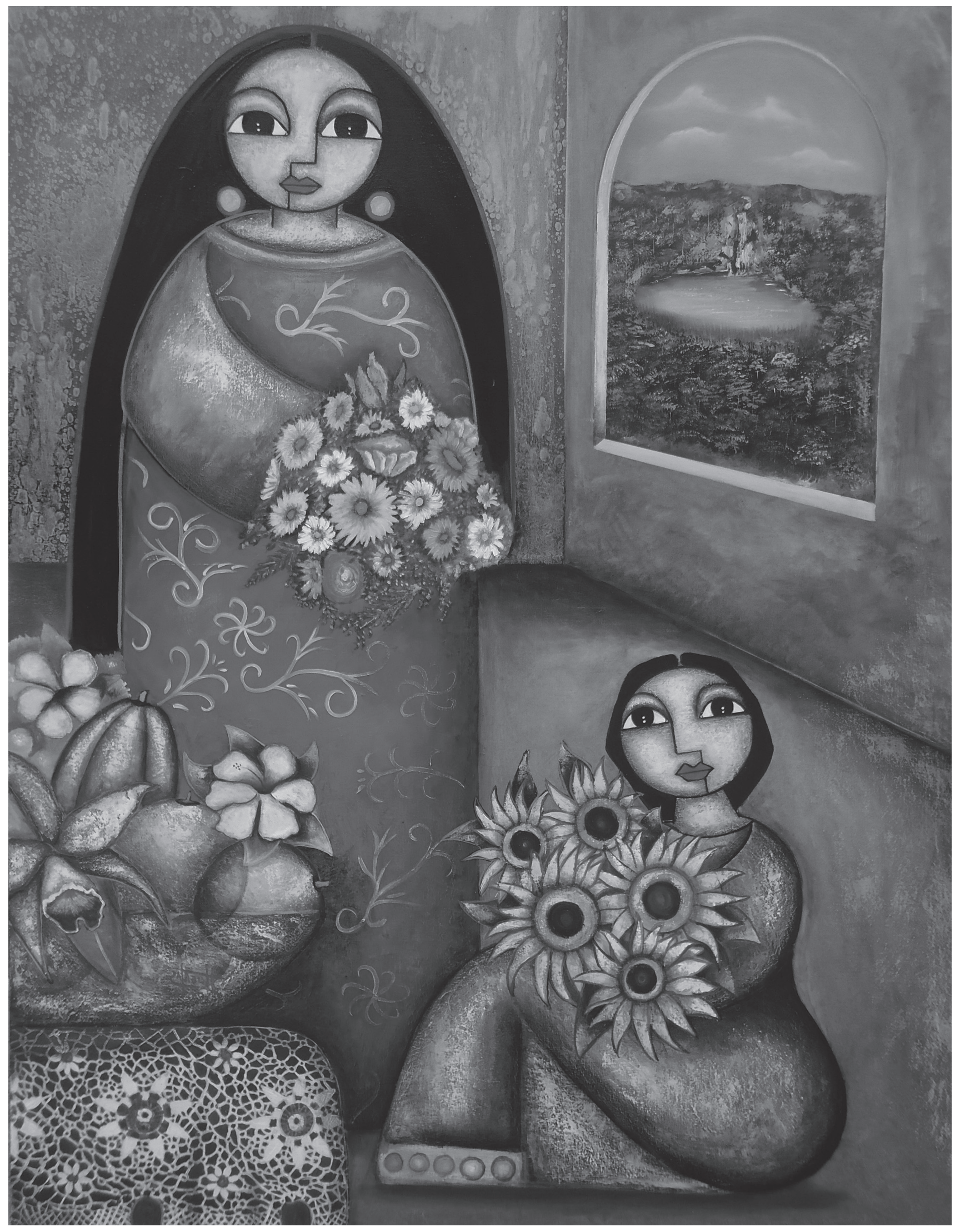

Segundo Arístides Huertas Torres ॥ Título: De la serie Vendedoras „)Técnica: Óleo sobre tela 》 Dimensiones: $110 \mathrm{~cm}$ x $100 \mathrm{~cm}$ 